\title{
The Research Progress on the Synthesis and Application of Microporous Coordination Polymers
}

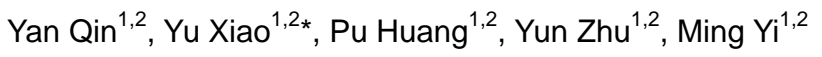 \\ 1. Guangxi Key Laboratory of Environmental Pollution Control Theory and Technology, Guilin University of Technology, Guilin 541004, \\ China; \\ 2. Guangxi Collaborative Innovation Center for Water Pollution Control and Water Safety in Karst Area, Guilin University of Technology, \\ Guilin 541004, China
}

\begin{abstract}
With the deepening of research, microporous coordination polymers, as a new type of molecule based materials, show potential application prospect. They have pore structure diversifications, high specific surface areas, unsaturated coordination sites and coordination mode diversifications, and their performance are better than the general pure inorganic porous materials and pure organic porous materials. Researchers have synthesized a large number of porous coordination polymers with different structures and properties by using different synthetic methods, different ligands and different metal ion reactions. At the same time, the application of their various properties such as gas storage, molecular separation, heterogeneous catalysis and nonlinear optical materials, are also gradually explored.
\end{abstract}

Microporous Coordination Polymers is usually a complex of metal ions and small molecule ligands by selfassembling and forming a highly structured network with unlimited network structure ${ }^{[1]}$. In recent years, the design and synthesis of novel metal organic coordination polymers have attracted more and more research on the development and utilization of materials ${ }^{[2-3]}$. This is due to their potential applications in catalysis, gas storage and separation, molecular recognition, magnetic, ion exchange and nonlinear optics ${ }^{[4-6]}$.

\section{Characteristics of microporous coordination polymer}

\subsection{Diversity of hole structure}

The hole of the coordination polymer is formed by the object molecules in the skeleton, and the length of the ligand and the volume of the guest molecules determines the size of the hole. Because of the structural diversity of organic ligands and the diversity of the distribution patterns of the metal ions, it can be used to construct a variety of hole shapes. By selecting different metal salts and various organic ligands, the coordination polymers (MOFs) with different pore shape and pore size are synthesized to meet the requirements of different applications.

\subsection{High specific surface area}

The specific surface area of inorganic zeolite porous materials and carbon-based materials is rarely more than $2000 \mathrm{~m}^{2} / \mathrm{g}^{[7]}$, but MOFs can reach a high specific surface area. Matzger et al. ${ }^{[8]}$ reported that the porous coordination copolymer (UMCM-2), BET specific surface area reached $5000 \mathrm{~m}^{2} / \mathrm{g}$. Yaghi et al. ${ }^{[9]}$ synthesized the MOF-177 and MOF-210, their BET specific surface area was $4500 \mathrm{~m}^{2} / \mathrm{g}$ and $6240 \mathrm{~m}^{2} / \mathrm{g}$.

\subsection{Unsaturated distribution site}

In the process of the synthesis of coordination polymers, the metal ions, due to steric hindrance and other reasons, also combine some small solvent molecules to meet the requirements of coordination number, such as methanol, ethanol, water or DMF. When heated or vacuum treatment of MOFs, the small molecule with the metal ion is pumped away. The coordination number of the metal ion is not reached saturation, which makes the MOFs have an acidic or alkaline position, so that it can play a catalytic role in the organic reaction.

\subsection{Diversity of coordination structures}

Since the metal ions with different coordination ability and numbers, while the different reaction conditions hereinafter metal ion will have a different coordination geometry, so the structure of the coordination polymer can be changed due to the different metal ions configuration. At the same time, the organic ligands have a variety of structures, such as carboxylic acid, pyridine type, and mixed type. Therefore, the synthesized MOFs has different topological structures, such as cubic, diamond, quartz, etc.

\section{Synthesis of microporous coordination polymer}

Microporous coordination polymers are usually prepared by conventional solution method, diffusion method (including gas, liquid layer and gel diffusion) and hydrothermal (solvent) synthesis. Among them, hydrothermal (solvent) synthesis is the most widely used. At the same time, in order to get more efficient and green preparation, microwave, ultrasonic wave and solid phase reaction method were introduced in the process of the preparation. 


\subsection{Solution method}

Solution method is a kind of self assembling method for the dissolution of metal salt and ligand in a certain proportion of solvent, which is suitable for the volatile solvent, and the solvent is slowly volatile to reach the saturated and precipitated crystal. Akhbari ${ }^{[10]}$ using the solution method to Schiff base ligands synthesized a new type of one-dimensional thallium ( I ) Coordination Polymer $\left\{[\mathrm{TI}(\mathrm{L})(\mathrm{HL})]\left(\mathrm{H}_{2} \mathrm{O}\right)_{0.77}\right\}_{\mathrm{n}}(\mathrm{HL}=4$ - hydroxy benzylidene-4-

amino benzoic acid). Derikvand et al. ${ }^{[11]}$ synthesized two new two-dimensional coordination polymer heterocyclic use solution method $\left\{(\text { dapH })_{2}\right.$ $\left.\left[\mathrm{CaM}_{2}(\text { pydc })_{4}\left(\mathrm{H}_{2} \mathrm{O}_{2}\right)\right] \cdot 2 \mathrm{H}_{2} \mathrm{O}\right\}_{\mathrm{n}}(\mathrm{M}=\mathrm{Ni}(1), \mathrm{M}=\mathrm{Zn}$ (2); pydcH $_{2}=$ pyridine-2,6-dicarboxylic acid, dap $=3,4-$ diaminopyridine).

\subsection{Diffusion method}

The vapor diffusion method is to dissolve metal salts and organic ligands in an appropriate solvent, and then let the volatile solvents diffuse into the solution so that it can reach the saturated and precipitate crystals. The liquid layer diffusion method is to dissolve metal salts and ligands in solvents of different densities, and then the solution was placed on an another solution, the two solutions in the contact surface and the precipitated crystals through diffusion reaction. Guo et al. ${ }^{[12]}$ synthesized a series of rare-earth porous coordination polymers $\mathrm{M}(\mathrm{bpdc}) 1.5\left(\mathrm{H}_{2} \mathrm{O}\right) \cdot 0.5 \mathrm{DMF}(\mathrm{M}=\mathrm{Tb}, \mathrm{Ho}, \mathrm{Er}, \mathrm{Y})$ by liquid layer diffusion. Gel diffusion method is one of the components (ligand) formulated in a gel, the solution of another component (metal) was placed on the gel, the two components by diffusion at the interface precipitate crystals. Yaghi et al. ${ }^{[13]}$ use of gel diffusion synthesized complexes $\mathrm{Cu}\left(1,4-\mathrm{C}_{4} \mathrm{H}_{4} \mathrm{~N}_{2}\right)$

$\left(\mathrm{C}_{4} \mathrm{O}_{4}\right)\left(\mathrm{OH}_{2}\right)_{4}$. The structure is composed of one-dimensional linear chains, and is connected by hydrogen bonds to a three-dimensional network structure, which is not obtained by other methods.

\subsection{Hydrothermal/Solvothermal}

Hydrothermal/solvothermal is to mix the reactants and solvents in a sealed system, usually stainless steel reactor (lined with polytetrafluoroethylene) and heated to a certain temperature, the reaction under autogenous pressure generated in the solvent. This method is compared to the previous two methods, the reaction will be faster, the low solubility of the reactants requirements, it can be synthesized coordination polymers by controlling a variety of factors, such as: the reaction temperature, time and solvent solute ratio. $\mathrm{Li}$ et al. ${ }^{[14]}$ synthesized a new rare earth coordination polymers $\left(\mathrm{H}_{2} \text { pipz }\right)_{3}\left[\mathrm{~Tb}_{2}(\text { pydc })_{6}\right] \cdot 15 \mathrm{H}_{2} \mathrm{O}$ (pipz $=$ piperazine, $\mathrm{H}_{2}$ pydc=pyridine-2,6-glycolic acid) by hydrothermal method, its structure is characterized by a novel $\left(\mathrm{H}_{2} \mathrm{O}\right)_{20}$ clusters constitute one-dimensional infinite chain, and by a large number of hydrogen bonds and $\pi-\pi$ stacking interactions connection into a three-dimensional supramolecular network structure. Xu Jiakun ${ }^{[15]}$ synthesis of 21 novel coordination polymers with $\mathrm{N}$-containing ligands and carboxylic acid ligands and transition metal ions under hydrothermal conditions.

\subsection{Microwave method}

The microwave can rapidly and uniformly heat the medium, resulting in an isotropic nucleation environment, which can lead to the nucleation and growth of the crystal rapidly, and lead to uniform particle size distribution. Liu et al. ${ }^{[16]}$ using the microwave method synthesized a series of new magnesium-pyromellitic acid $\left(\mathrm{H}_{4} \mathrm{BTEC}\right)$ coordination polymers: $\left[\mathrm{Mg}_{2}(\mathrm{BTEC}) \quad\left(\mathrm{H}_{2} \mathrm{O}\right)_{4}\right] \cdot 2 \mathrm{H}_{2} \mathrm{O}$,

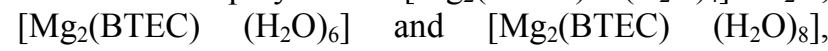
respectively for the three-dimensional, two-dimensional and one-dimensional structure, the size of the resulting product is between $0.01 \sim 0.5 \mathrm{~mm}$. Delgado et al. ${ }^{[17]}$ in the power of $600 \mathrm{~W}$ microwave irradiation, the reaction mixture is heated to $140^{\circ} \mathrm{C}$ within $20 \mathrm{~min}$ and maintain $2 \mathrm{~h}$, got a one-dimensional coordination polymer connected by a cage-like $\mathrm{Cu}_{9}\left\{\left[\mathrm{Cu}_{9}\left(\mathrm{C}_{5} \mathrm{H}_{5} \mathrm{NS}\right)_{8}(\mathrm{SH})_{8}\right]\left(\mathrm{BF}_{4}\right)\right\}_{\mathrm{n}}$, which has good conductivity, is one of the few conductive coordination polymers.

\subsection{Ultrasonic method}

The reaction solution under the action of ultrasonic waves, the liquid medium is formed tiny bubbles, after experiencing rapid growth and collapse, oscillation process, produce very short high temperature and pressure and high local temperature gradients, and high-speed microjets, and the resulting high-speed molecular motion, activated reactive sites and can promote self-assembling molecules. Qiu et al. ${ }^{[18]}$ was synthesized nanoscale porous coordination polymers $\mathrm{Zn}_{3}(\mathrm{BTC})_{2} \cdot 12 \mathrm{H}_{2} \mathrm{O} \quad(\mathrm{BTC}=$ benzene-1,3,5-TriCarboxylic acid) by ultrasound, the compound can be used to detect organic amine. Haque et al. ${ }^{[19]}$ were used ultrasonic, microwave and conventional heating synthesis CPO-27s material, obtained the material properties of the hole (specific surface area and pore volume) relationship and nucleation, crystal growth rate is the ultrasonic method $>$ microwave Method > conventional heating methods.

\subsection{Solid phase synthesis method}

The organic ligands and metal salts are mixed evenly and milled to prepare a "no" solvent of the coordination polymer. This method is suitable for the use of the amount of material required. Braga et al. ${ }^{[20]}$ was used solid-phase synthesized one-dimensional chain coordination polymer $\left[\mathrm{CuCl}_{2} \text { (dace) }\right]_{\infty}($ dace $=$ trans-1,4-Diaminocyclohexane $)$ and $\mathrm{Zn}\left[\mathrm{N}\left(\mathrm{CH}_{2} \mathrm{CH}_{2}\right)_{3} \mathrm{~N}\right] \mathrm{Cl}_{2}$. Pichon et al. ${ }^{[21]}$ for the first time using this method for the synthesis of $\mathrm{Cu}$ isonicotinic metal coordination polymer material. Muller et al. ${ }^{[22]}$ use the same method was synthesized Zn-BDC and $\mathrm{Cu}-\mathrm{BDC}$ skeletal material. 


\section{Application of Microporous Coordination Polymers}

Microporous coordination polymers have the characteristics of both organic ligands and central metal ions, and this kind of compound has a certain shape of the pore structure, which has potential applications in gas storage, molecular separation, heterogeneous catalysis, nonlinear optical materials and so on.

\subsection{Catalysis}

Unique pore structure and the potential catalytic properties of the transition metal ions have provided the necessary conditions for the microporous coordination polymer as a catalytic material. Such as the synthesis of propylene oxide ${ }^{[23]}$, with MOF-5 as the catalyst, the mixture of oxygen, helium and propylene $10 \mathrm{~h}$ reaction, the yield was $4.3 \%$, the selectivity was $8.2 \%$. Muller et al. ${ }^{[24]}$ using diethylene glycol and propylene oxide synthesized Polyhydroxy compounds with MOF-5 as alkoxylation catalyst; Similarly, with ethylene oxide to a ethylene propylene glycol were alkoxylation, it has also been a polyhydroxy compounds. Seo et al. ${ }^{[25]}$ synthesized the chiral polymer materials and developed its chiral catalysis.

\subsection{Gas storage}

A new type of microporous polymer material with a stable nano scale pore structure, with a special pore structure, a certain pore volume and a large specific surface area, is in a crystalline or amorphous form of porous material can make some molecules in the surface of the pores in the passage. This makes them a promising application prospect in terms of gas storage, which is mainly concentrated on the fuel gas, such as methane and hydrogen. Rosi et al. ${ }^{[26]}$ first studied MOFs as hydrogen storage materials, they were measured $78 \mathrm{~K}$ and $298 \mathrm{~K}$ in IRMOF-1 hydrogen adsorption capacity by gravimetric method, the hydrogen storage capacity (mass fraction) reached $4.5 \%$ when the temperature was $78 \mathrm{~K}$ and maximum pressure was $7.5 \times 10^{4} \mathrm{~Pa}$; and hydrogen absorption (mass fraction) of $1 \%$ when the the temperature was $298 \mathrm{~K}$ and the pressure was $2 \times 10^{6} \mathrm{~Pa}$. They think that the organic coupling in the framework is the most important in determining the amount of hydrogen adsorption, IRMOF- 6 and IRMOF- 8 have more connections than IRMOF-1, and the hydrogen adsorption capacity of $1 \times 10^{6} \mathrm{~Pa}$ and $298 \mathrm{~K}$ are 2 times and 4 times of hydrogen adsorption in IRMOF-1 respectively, the hydrogen absorption is much greater than that of the typical active carbon and $\mathrm{SWNT}$. In 2000, $\mathrm{CuSiF}_{6}(\mathrm{BPy})_{2}$, as the first to study the $\mathrm{CH}_{4}$ adsorption of the coordination polymer, under the condition of $298 \mathrm{~K}$ and pressure of 36 atm, the adsorption capacity of $\mathrm{CH}_{4}$ is $104 \mathrm{mg} / \mathrm{g}^{\text {[27] }}$.

\subsection{Selective adsorption and separation of gases}

Microporous coordination polymer material with special pore structure and surface properties, the adsorption capacity of different gases are different, it can be used for selective adsorption of gas mixture, so as to realize the separation and purification of gas. In 2008, the Yaghi research group ${ }^{[28]}$ reported that $\mathrm{Mg}-\mathrm{MOF}-74$ was able to effectively absorb $\mathrm{CO}_{2}$ from the mixture of $\mathrm{CO}_{2}$ and $\mathrm{CH}_{4}$, and the adsorption capacity reached $8.9 \mathrm{wt} \%$, which released $87 \%$ of $\mathrm{CO}_{2}$ at room temperature, and was heated to $80^{\circ} \mathrm{C}$ released completely. In 2013, Jeffrey R. Long research group ${ }^{[29]}$ reported the $\mathrm{Fe}_{2}(\mathrm{BDP})_{3}\left(\mathrm{BDP}^{2-}=\right.$ 1,4-benzenedipy razolate) with a triangular channel on Science, it is able to separate the hexane homologues according to the number of branched chains.

\subsection{New luminescent material}

In MOFs, because of the coordination of the metal, the emission wavelength of organic ligands will be significantly affected, and the fluorescence properties of organic ligands are different from that of the corresponding organic ligands. The stability of MOFs is higher than that of pure organic ligands, which can be controlled the color, intensity, fluorescence lifetime and efficiency of the luminescence by changing the metal ion, organic ligand and adjusting conjugated system, so as to obtain new luminescent materials. In 2012, Cepeda ${ }^{[30]}$ used 4, 6-two carboxylic acid synthesized a series of three-dimensional rare earth coordination polymers with jcr2 topology, and the fluorescence lifetimes of the series coordination polymers were longer than that of the same ligands. This may be due to the decrease of the fluorescence quenching of $\mathrm{O}-\mathrm{H}$ by reducing the coordination of water molecules in the coordination polymer. Emission efficiency of the order of the central ion is $\mathrm{Tb}$ (III) $>\mathrm{Eu}$ (III) $>\mathrm{Nd}$ (II), which is the energy difference between the metal ions concerned.

\subsection{Magnetic materials}

By choosing appropriate bridging ligand, Co ligands and different anisotropic paramagnetic magnetic metal ion synthesis of novel magnetic coordination polymers. As with terephthalic acid as organic bridging ligands of four and five coordinated two-dimensional drill coordination polymer between the $300-41 \mathrm{~K}$ with ferromagnetic ${ }^{[31]}$. Ferey group ${ }^{[32]}$ on the magnetic MIL Series coordination polymers were studied, some of which contain cobalt, iron coordination polymer having a ferromagnetic transition temperature at $10 \mathrm{~K}$ and $20 \mathrm{~K}$, such as $\mathrm{K}\left[\mathrm{M}_{3}(\mathrm{BTC})_{3}\right] \cdot 5 \mathrm{H}_{2} \mathrm{O}(\mathrm{M}=\mathrm{Co}, \mathrm{Fe})(\mathrm{MIL}-45)$.

\section{Summary and Outlook}

Microporous coordination polymer is a kind of important new type of molecular material because of its novel structure and unique physical and chemical properties. They have potential applications in catalysis, gas storage and separation, molecular recognition, magnetic and non-linear optics and other fields. The researchers used different synthesis methods, ligands and metal ions to synthesize a large number of porous polymer with 
different structures and properties. However, the quantitative relationship between the molecular structure of the predetermined structure, the directional assembly (Crystal Engineering) and the molecular structure and properties of the expected functional microporous complexes is still one of the most challenging problems in the chemistry. There are still many problems to be solved in order to realize the industrialization production and application of this new material. In short, microporous coordination polymer as a new type of functional porous material has received widespread attention, I believe in the near future, this new material will bring more convenience to our life, and become an indispensable part of our life.

\section{Acknowledgment}

The study of this paper was supported by fund: Guangxi Scientific Experiment Center of Mining, Metallurgy and Environment \& The Guangxi Talent Highland for Hazardous Waste Disposal Industrialization

\section{Reference}

[1] Battem S R, Robson R. Angew. Chem. Int. Ed. 37, 11 (1998)

[2] Deng H, Doonan C J, Furukawa H, et al. Science, 327, 5967 (2010)

[3] Shao K Z, Zhao Y H, Wang X L, et al. Inorg Chem, 48, 1 (2009)

[4] Matsuda R, Kituara R, Kitagwaa S, et al. Nature, 436, 7048 (2005)

[5] Seo J S, Whnag D, Lee H, et al. Nature, 404, 982 (2000)

[6] Chester A W, Clement P, Han S. Faujasite zeolitic materials[P], US 6136291, 2000-10- 24.

[7] Nijkamp M G, Raaymakers J E, van Dillen A J, et al. Applied Physics ArMaterials Science\&Processing, 72, 5 (2001)

[8] Matzger A J, Koh K, Wong-Foy A G, et al. J. Am. Chem. Soc., 131, 12 (2009)

[9] Yaghi O M, Millward A R. J.Am. Chem. Soc., 127, 51 (2005)

[10] Akhbari K, Alizadeh K, Morsali A, et al. Inorganica
Chimica Acta, 362, 8 (2009)

[11] Derikvand Z, Bruno G, Rudbari H A. et,al. Inorganica Chimica Acta, 410, 30 (2014)

[12] Guo M Y, Xiong G, Sun Y G, et, al. Coordination Chemistry in China, 83 (2014)

[13] JesseL C, Rowsell O M, Yaghi. Angew. Chem. Int. Ed., 44, 30 (2005)

[14] Li M, Feng R, Huang Q Z, et al. Inorganic Chemistry Communications, 50 (2014)

[15] Xu J K.. Ocean University of China, 2014.

[16] Liu H K, Tsao T H., Zhang Y T, et al. Cryst EngComm, 11, 7 (2009)

[17] Delgado S, Sanz Miguel P J, Priego J L, et al. Inorg Chem , 47, 20 (2008)

[18] Qiu L G, Li Z Q, Wu Y, et al. Chem Commun , 31 (2008)

[19] Haque E. Jhung S H. Chemical Engineering Journal, 173, 3 (2011)

[20] Braga D, Giaffreda S L, Grepioni F, et al. CrystEngComm, 6, 75 (2004)

[21] Pichon A, Lazuen-Garay A, James S L. CrystEngComm, 8, 3 (2006)

[22] Muller U, Hesse M, Lobree L, et al. US 2004/009724, (2004)

[23] Muller U, Stober M, Yaghi O M, et a1. US 0078 311, (2003)

[24] Muller U, Hesse M, Lobree L, et a1. US 097724 Al, (2004)

[25] Seo J S, Whang D, Lee H, et a1. Nature, 404, 6781

[26] Rosi N L, Eckert J, Eddaoudi M, et a1. Science, 300 (2003)

[27] Noro S, Kitagawa S, Kondo M, Seki K. Angew. Chem. Int. Ed., 39, 12 (2000)

[28] Caskey S R, Wong-Foy A G, Matzger A J. J. Am. Chem. Soc., 130, 33 (2008)

[29] Herm Z R, Wiers B M, Mason J A, et al. Science, 340, 6135 (2013)

[30] Cepeda J, Balda R, Beobide G, et al. Inorg Chem, 51, 14 (2012)

[31] Zhang L J, Zhao X L, Cheng P, et al. Chem. Soc., 76, 6 (2003)

[32] Kondo M, Shimamura M, Noro S, et al. Chemistry of Materials, 12, 5 (2000) 